\title{
POLÍTICAS EDUCACIONAIS: APROXIMAÇÕES ENTRE ENSINO MÉDIO, EJA E EDUCAÇÃO PROFISSIONAL
}

\author{
POLÍTICAS EDUCATIVAS: ENFOQUES ENTRE LA ESCUELA SECUNDARIA, \\ EDUCACIÓN DE JÓVENES Y ADULTOS (“EJA”) Y EDUCACIÓN \\ PROFESIONAL
}

\section{EDUCATIONAL POLICIES: APPROACHES AMONG HIGH SCHOOL, ADULT AND YOUTH EDUCATION AND PROFESSIONAL EDUCATION}

\author{
Simone Gonçalves SILVA ${ }^{1}$ \\ Cinara Martins Farina ALLEMAND ${ }^{2}$ \\ Antonio Cardoso OLIVEIRA ${ }^{3}$ \\ Maria Fátima CÓSSIO ${ }^{4}$
}

RESUMO: O presente artigo objetiva analisar as tendências, as especificidades e as convergências nas pesquisas em políticas educacionais, especificamente com relação às possíveis aproximações e articulações sobre o Ensino Médio, a Educação de Jovens e Adultos e a Educação Profissional. Para tanto, utiliza-se como fonte de análise os artigos apresentados sobre os referidos subtemas na modalidade de comunicação oral do eixo temático "Políticas da educação básica", no II seminário da ANPAE - região sul, realizado em novembro de 2012. Como metodologia utilizou-se a pesquisa teórica e para a análise dos trabalhos foram construídas categorias, considerando as principais recorrências. A reflexão apresentada ressalta a importância dos debates e a contribuição para o campo de estudos das políticas educacionais.

PALAVRAS-CHAVE: Políticas educacionais. Educação Básica. Discussões recorrentes.

RESUMEN: Este artículo tiene como objetivo analizar las tendencias, las especificidades y convergencias en la investigación sobre la política de la educación, específicamente con respecto a los posibles enfoques y las articulaciones de la Escuela Secundária, Educación de Jóvenes y Adultos y Educación Profesional. Por lo tanto, se utiliza como fuente de análisis de los artículos que se presentan en estos subtemas en el modo de comunicación oral del tema principal "Políticas de educación básica" en el II seminario ANPAE - região sul, celebrada en noviembre de 2012. La metodología se utilizó la investigación teórica y para la análisis de textos fueron construídos categorias, teniendo en cuenta los principales recurrencias. La

1 Doutoranda do Programa de Pós-Graduação em Educação da UFPel. Email: simonegonsilva@yahoo.com.br

2 Mestra em Políticas Sociais, do Programa em Políticas Sociais da Universidade Católica de Pelotas, UCPEL. Email: cinarafarina@yahoo.com.br

${ }^{3}$ Doutorando em Educação. É professor do ensino básico, técnico e tecnológico do Instituto Federal SulRio-Grandense. Desempenha a função de Coordenador do Curso Superior de Tecnologia em Gestão de Cooperativas. Sendo também Coordenador Geral da Rede e-Tec Brasil no IFSul. É membro do Grupo de Pesquisa em Gestão, Currículo e Políticas Educativas da FAE/UFPEL e membro do Grupo de Pesquisa em Educação a Distância - GPE@D. Email: antoniooliveira_ifsul@yahoo.com.br

${ }^{4}$ Docente da Faculdade de Educação/UFPEL. Mestre e Doutora em Educação na linha de Gestão e Políticas de Educação pela UFRGS/RS. Pós-doutora em Educação pela UFSC/SC na Linha de Pesquisa Educação, Estado e Políticas Públicas. Professora da Faculdade de Educação/UFPEL. Email: fatimacossio@ig.com.br 
reflexión presentado pone de relieve la importancia de los debates y de la contribución en el campo de estudio de las políticas educativas.

PALAVRAS CLAVE: Políticas educativas. Educación básica. Discusiones recurrentes.

ABSTRACT: This article aims to analyze trends, specificities and convergences in researches on educational policies, specifically regarding to possible approaches and articulations about High School, Adult and Youth Education and Professional Education. Thus, it is used as a source of analysis articles presented on these subtopics in the form of oral communications under the topic: "Primary Education Policies" in ANPAE II seminar-, Southern region, held in November, 2012. It was used theoretical research as methodology and for paper analysis were built categories, considering the main recurrences. The reflection presented highlights the importance of debates and contribution to the field of educational policy studies.

KEYWORDS: Educational policies. Primary education. Recurrent discussions.

\section{Introdução}

Este artigo discute as políticas educacionais, procurando contribuir com reflexões sobre as preocupações mais evidentes e convergentes nas produções científicas apresentadas no II seminário da ANPAE - região sul. A pesquisa realizada é um recorte de uma análise mais ampla sobre os artigos apresentados na modalidade de comunicação oral, do eixo temático "Políticas da educação básica", no referido seminário, realizado em dezembro de $2012 \mathrm{em}$ Pelotas/RS. Tais fontes fazem parte do universo de sessenta e seis trabalhos disponíveis no CD-ROM do evento. Devido ao grande número de pesquisas acadêmicas nessa área, a pesquisa foi dividida em seis subtemas: Formação de Professores; Qualidade da Educação; Parcerias PúblicoPrivadas; Gestão da Educação; Educação Infantil; Ensino Médio, Educação de Jovens e Adultos e Educação Profissional.

Diante disso, o referido estudo objetiva analisar e compreender as tendências, especificidades e convergências nas pesquisas em políticas educacionais dos três estados da região sul, especificamente com relação às possíveis aproximações e articulações nos trabalhos apresentados sobre Ensino Médio, Educação de Jovens e Adultos e Educação Profissional. Para tanto, a investigação apresentada, de natureza qualitativa, caracteriza-se como teórico-bibliográfica, e para análise dos dados utilizamse os pressupostos da análise de conteúdo, notadamente na construção das categorias, a partir das principais recorrências identificadas nos artigos. 
O trabalho está estruturado da seguinte maneira: na primeira parte destacou-se a importância das pesquisas sobre as políticas educacionais no contexto atual. Posteriormente, analisaram-se, a partir da leitura dos artigos na íntegra, as temáticas abordadas nas principais discussões. Por fim, destacou-se a reflexão e as proposições das políticas educacionais analisadas e ratificou-se a importância dos estudos e debates como fomento para o campo do estudo crítico das políticas educacionais.

\section{Políticas Educacionais: uma discussão pertinente}

As políticas públicas educacionais são as estratégias desenvolvidas pelos governos na busca de determinados fins específicos no campo da educação. Estas refletem as concepções dos diferentes sujeitos que estão envolvidos no processo decisório, em um dado período e sob diferentes variáveis de um contexto. Em outro trabalho, afirmou-se que o “[...] conceito de políticas educacionais vai além das questões de ordem legal, mas as inclui, denotando claramente as perspectivas e intencionalidades de cada tempo histórico e dos grupos que detêm o poder" (CÓSSIO, 2010, p.01).

Diante disso, nesse campo de estudos, reconhece-se cada vez maior o número de planos e programas que estão sendo efetivados na esfera educacional, com destaque para os emanados do governo central. Constituem, em seu conjunto, em políticas indutoras da qualidade, direcionadas para os sistemas ou redes de ensino e/ou diretamente para as escolas.

Assim, percebe-se como importante a realização de pesquisas que analisem e avaliem essas políticas, visto que a efetivação desses estudos possibilita a identificação das motivações para a inserção de determinadas demandas na agenda política e, principalmente, quais são os resultados dessas políticas públicas em termos de impacto na vida da população. Acredita-se que "Analisar as políticas públicas para a educação no contexto atual implica no esforço de compreensão das motivações políticas em escala mundial e suas repercussões locais, não se caracterizando, portanto, numa análise circunstancial e particularizada" (CÓSSIO, 2010, p. 01).

Diferentes questões emergem quando se pretende pesquisar temas inerentes às políticas educacionais, tendo em vista a relevância, a abrangência e a complexidade com que se revestem, ainda mais quando pretendem construir alternativas que visualizem a 
construção de um país menos desigual. Ao enfatizar a relevância de se almejar algo diferente e melhor para futuro, surge a necessidade de se abordar a discussão de emancipação social. Conforme Santos (2007, p.37), que afirma que "há a necessidade de emancipação social, mas que é preciso reinventá-la”.

\begin{abstract}
O problema é que não podemos continuar pensando a emancipação social em termos modernos, pois os instrumentos que regulam a discrepância entre reforma e revolução, entre experiências e expectativas, entre regulação e emancipação, essas formas modernas, estão hoje em crise. Entretanto, não está em crise a idéia de que necessitamos de uma sociedade melhor, de que necessitamos de uma sociedade mais justa. As promessas da modernidade - a liberdade, a igualdade e a solidariedade - continuam sendo uma aspiração para a população mundial (SANTOS, 2007, p.37).
\end{abstract}

Uma educação que pretenda colaborar com a emancipação social deve valorizar o conceito e a prática da democracia, ou seja, precisa levar em conta o incentivo às diferenças, a ampliação dos espaços e processos de participação na tomada de decisões sobre a vida em sociedade e a garantia de direitos. É através do estímulo ao surgimento de diferentes concepções e ações, que se possibilita a reconstrução da sociedade.

\title{
Análise das produções sobre Ensino Médio, Educação de Jovens e Adultos e Educação Profissional
}

Neste texto, realizou-se, conforme mencionado, uma análise das produções do eixo temático 01 - Políticas da Educação Básica, ANPAE - região sul, relacionadas aos subtemas Ensino Médio, Educação de Jovens e Adultos e Educação Profissional.

Com relação à descrição metodológica dos trabalhos, no que concerne à análise dos artigos que objetivaram o estudo das políticas educacionais no contexto do Ensino Médio, os quais totalizaram sete trabalhos, verificou-se que as pesquisas realizadas são preponderantemente bibliográficas (quatro das sete analisadas), contendo também duas pesquisas documentais, um trabalho bibliográfico-documental e um estudo de caso. $\mathrm{O}$ estudo analítico desses trabalhos constatou que quatro dos sete artigos fazem parte de pesquisas mais amplas e em andamento, sendo que três desses quatro trabalhos estão sendo realizados por grupos de pesquisas vinculados às Universidades, referentes aos cursos de Mestrado e Doutorado. Quanto à metodologia utilizada, quatro das sete 
pesquisas discorreram seus estudos de forma analítica, e as outras três se ancoraram na metodologia descritivo-analítica.

As análises desenvolvidas da produção referente à modalidade de Educação de Jovens e Adultos foram organizadas tendo por base o total de oito trabalhos. Nestes, identificou-se que as tipologias são: cinco pesquisas teóricas, duas pesquisas de campo, um relato de experiência. Destaca-se que as pesquisas são fruto de projetos de pesquisa das Universidades, trabalhos de conclusão de especialização e recortes de dissertações de Mestrado. As metodologias empregadas nas pesquisas consistem em quatro analíticas, duas analíticas propositivas e duas descritivas.

Quanto ao estudo dos artigos referentes à Educação Profissional, totalizados em oito trabalhos, analisou-se que o tipo de pesquisa utilizado também se concentrou no estudo bibliográfico (seis dos oito trabalhos), contendo também dois estudos de caso. Apenas um trabalho cita a efetivação de uma pesquisa qualitativa e de análise de conteúdo. Verificou-se, também, que dois trabalhos fazem parte de dissertações de Mestrado e outros dois foram produzidos por grupos de pesquisa. Os demais são frutos dos estudos de pessoas envolvidas no contexto profissional da educação.

O trabalho de pesquisa nos vinte e três artigos consistiu, a princípio, na verificação das categorias de cada um dos artigos. Após, para fins de uma melhor objetivação do trabalho proposto, as várias categorias foram agrupadas e condensadas em três grandes temas recorrentes nas pesquisas, a partir das relevâncias comuns constatadas nos textos verificados. São eles: As transformações no mundo do trabalho e as suas relações com a educação; As políticas educacionais a partir das últimas reformas: as redefinições no papel do Estado; A formação do trabalhador: o trabalho como princípio educativo.

A seguir, esses três grandes temas serão analisados separadamente.

\section{As transformações no mundo do trabalho e as suas relações com a educação}

As alterações objetivas da ordem econômica, neste estágio particular do capitalismo, explicitam-se nas políticas atuais para o Ensino Médio, para a Educação de Jovens e Adultos e para a Educação Profissional em desenvolvimento no Brasil. Nesta perspectiva, a educação é pautada pelas exigências de competitividade, produtividade e de inovação do sistema produtivo, agora aberto e sem fronteiras.

RIAEE - Revista Ibero-Americana de Estudos em Educação, v. , n. , p. , 2017. $\quad$ E-ISSN: 1982-5587 
As políticas educacionais, estruturadas com base nas relações de trabalho, são influenciadas fortemente pelas relações internacionais de mercado. Nesse sentido, vale lembrar os ensinamentos de Marx (1975, p. 284) para quem: "A sociedade capitalista está estruturada e organizada sobre o trabalho. Nesse tipo de sociedade os homens têm vínculos sociais com todas as pessoas da terra, sobre ou sob a égide do trabalho". Significa dizer, portanto, que é imprudência analisar as políticas educacionais sem relacioná-las às condições em que os homens produzem e definem as relações sociais de trabalho. Essas relações resultam das metamorfoses que o mundo do trabalho está vivendo, e fundamentam a exigência de um novo perfil de trabalhador, mais qualificado e forjado para um mercado muito mais competitivo. Este novo profissional é nomeado perspicazmente por Antunes (1999, p. 52) de “operário-técnico", em decorrência da continuidade de sua condição social, mas noutro padrão de exigência.

A complexidade do mundo do trabalho, segundo Antunes (1999, p. 54), demonstra uma "processualidade contraditória". De um lado, o incremento da intelectualização do trabalho, em que a qualificação é considerada força motriz, e, no lado inverso, a condição desqualificada e subproletarizada dos trabalhos considerados precários.

Como reflexo das complexidades e diversidades da sociedade contemporânea, a política pública de incentivo à formação profissionalizante no Brasil vem se ajustando à perpetuação dos mecanismos sociais de seleção como forma de pretenso "acesso rápido" ao trabalho para aqueles que não podem "perder tempo" prosseguindo nos estudos, e, garantindo assim, uma possível forma de sobrevivência.

Nesse sentido, a formação técnica pode ser considerada como uma categoria intermediária de estudo ao novo operariado, proporcionando maior qualificação aos menos favorecidos, mas mantendo o privilégio do acesso ao ensino acadêmico de qualidade àqueles que, inseridos numa pequena fatia, continuarão no topo hierárquico dos postos de trabalho.

A condição de ascensão social, pautada na meritocracia, justifica a articulação entre mercado e educação. Os dispositivos que regulamentam o Ensino Técnico demonstram esta concepção, subsidiando a tendência de flexibilização produtiva, formativa e das relações de trabalho.

Segundo os Referenciais Curriculares Nacionais da Educação Profissional de Nível Técnico, 
Como uma das decorrências do intenso processo de reorganização produtiva pelo qual passa a sociedade brasileira, processo este ainda não concluído, os especialistas em Gestão podem se estruturar de forma a oferecer, autonomamente ou como pequenos empresários, seus serviços às organizações existentes. Podem, ainda, atender a um contingente crescente de profissionais de diferentes áreas que, ao romperem seu vínculo empregatício com as organizações nas quais trabalhavam, também passaram a trabalhar por conta própria, quer como profissionais autônomos, quer como titulares ou sócios de pequenas ou microempresas (BRASIL, 2000, p. 14).

Os discursos presentes nos textos das políticas educacionais remetem à formação de aspectos gerais no desenvolvimento dos futuros trabalhadores, preocupando-se com a “formação do caráter" e com a "participação cidadã". Considera-se que tal intenção denota, para além da redução dos conceitos de caráter e cidadania e das suas reformulações a partir dos princípios mercadológicos, uma justificativa de que a educação direcionada às necessidades de mercado promove diretamente $\mathrm{o}$ desenvolvimento geral da nação.

Segundo Ferretti (2002), este duplo sentido primeiramente remete ao consenso de que, à medida que a produtividade da economia cresce, toda a população é beneficiada, pois supostamente se elevam as condições de vida dos brasileiros. Como segundo sentido, o discurso intenciona justificar tal submissão formativa com o aumento do nível cultural da população, uma vez que postula uma educação geral de boa qualidade para todos, significando, dessa forma, um maior potencial de empregabilidade. Assim, constata Ferreti, esse discurso busca sedimentar no consenso da nação que "os interesses da produção se identificam com os interesses não só nacionais, mas também com os de cada trabalhador individual" (FERRETTI, 2002, p. 115).

Sabe-se que a prerrogativa de que os interesses de mercado conciliam os interesses dos trabalhadores não passa de um mecanismo - e que infelizmente consegue obter respaldo de grande parcela da população - para introjetar valores pragmáticos, que advém dessa lógica economicista, construindo no ser humano a própria identidade de "microempresa", com metas individualizadas e sustentadas no próprio mérito e na competitividade para a sua obtenção. A perversidade maior desse sistema é instigar o convencimento de que o alcance do sucesso financeiro é, nessa perspectiva, o objetivo final da realização humana.

Ciavatta (1998, p. 74) afirma que a formação profissional brasileira vem sendo decidida no campo técnico-empresarial, no âmbito mercadológico, reduzindo a 
educação dos trabalhadores à Educação Profissional. Neste conceito hegemônico de educação, a universalidade da cultura é preconizada como forma necessária à reprodução social, na qual se inclui o universo do trabalho. A Educação Profissional, como elemento da produtividade capitalista, além de pouco abranger o universo de conhecimentos necessários à vida humana, tem sido acompanhada de um valor que discrimina trabalhadores produtivos e improdutivos. $\mathrm{O}$ primeiro tipo contribui efetivamente para a sociedade, atualizando permanentemente suas competências, habilitando-se ao emprego. Já o segundo trabalhador carrega o estigma de fracassado, pois, ao não desenvolver as competências exigidas pelo mercado de trabalho, este o exclui.

Frente a essa realidade, o Ensino Médio, a Educação de Jovens e Adultos e a Educação Profissional se adaptam, acirradamente, à lógica de formação para o desenvolvimento de atributos individuais, necessários à possível obtenção de emprego, deslocando da educação a responsabilidade de um projeto de sociedade para pretensos projetos individuais cada vez mais restritos às necessidades de subsistência e consumo.

De acordo com Cruz (1999, p. 188-189), é imprescindível se descortinar os aspectos ideológicos da realidade do mundo do trabalho, base que sustenta a formação profissional e a educação como um todo, para que se consiga diagnosticar os limites e os problemas das atuais políticas educacionais.

Através da análise das influências desse modelo econômico nas atuais políticas educacionais, constata-se que a racionalidade técnica, cada vez mais cultivada como competência nas relações de trabalho, dá ênfase ao consenso, evitando confrontos e supervalorizando a administração racional da vida e, desse modo, determinando as possibilidades de existência a partir da perda do controle humano sobre o trabalho, tornando-o produto utilizável dessa nova ordem.

\section{Políticas educacionais a partir das últimas reformas: redefinições no papel do Estado}

A teoria do Estado é determinante para que se possa entender os diversos estágios e as principais mudanças que ocorrem no campo político, econômico e social. Esses estudos mostram quais foram as principais alterações e reconfigurações dos 
modelos políticos assumidos pelos governos e nações, colaborando no processo de análise dos impactos dessas mudanças na sociedade em cada tempo/espaço.

Ao analisar as alterações do papel do Estado e refletir sobre as reconfigurações deste nos países capitalistas, Barroso (2005, P.741) aponta que:

\begin{abstract}
Após a Segunda Guerra Mundial, assistiu-se a um crescente aumento do poder e intervenção do Estado (quer sob a forma perversa dos totalitarismos, quer sob a forma protetora e desenvolvimentista do Estado Providência). Finalmente, a partir dos anos de 1980, através do tatcherismo e do regganismo, assistiu-se ao surgimento das chamadas "políticas neoliberais" (com a redução do papel do Estado e a criação de mercados, ou quase-mercados, nos setores tradicionalmente públicos - saúde, educação, transporte etc.). Estas "políticas neoliberais" afetaram diretamente muitos outros países e foram adotadas como referenciais para programas de desenvolvimento conduzidos pelas grandes organizações internacionais (FMI, Banco Mundial, OCDE etc.) no que foi designado por "consenso de Washington", cujas principais "receitas" passavam por: disciplina orçamental, reforma fiscal, eliminação das barreiras às trocas internacionais, privatização e desregulamentação, com o conseqüente apagamento da intervenção do Estado (BARROSO, 2005, p. 741).
\end{abstract}

A história permite compreender que o capitalismo ao longo do tempo sofreu reconfigurações em seu modelo. Estas alterações automaticamente se refletem nas transformações ocorridas com o papel do Estado.

$\mathrm{O}$ atual modelo apresentado pelo capitalismo vem se desenvolvendo de forma gradual, com a intenção de diminuir os efeitos das concepções neoliberais e satisfazer algumas aspirações dos defensores do movimento socialdemocrata. O denominado "capitalismo humanizado", ou projeto político da Terceira Via, tem como objetivo reduzir as diferenças entre Estado e mercado. Busca a atuação mais acentuada da sociedade em problemáticas que originalmente deveriam ser de responsabilidade exclusiva do Estado, criando com isso a figura do público não-estatal, ou terceiro setor, para atuar de forma efetiva, principalmente nas questões sociais.

Neste novo modelo, o Estado configura-se importante,

No equilíbrio das contas públicas, na garantia do controle à inflação, na liberalização econômica, enfim, criando condições para a expansão do modelo, e, portanto, exercendo um papel forte do ponto de vista econômico. No campo social, no entanto, passa a se utilizar da lógica comunitarista e do voluntariado, tendo como seus principais mecanismos a descentralização, a transferência de responsabilidades, criando novas categorias de oferta do serviço público, identificado com o "público não-estatal" que seria a oferta privada de serviços públicos, com o financiamento do Estado (CÓSSIO, 2012, p.03). 
Apresentando, assim, as principais estratégias da "nova pedagogia da hegemonia", destacam-se algumas práticas do Estado, esse denominando "Estado neoliberal da Terceira Via", como a predominância de interesses específicos nas legislações e concepções, estratégias regulatórias destinadas à classe que vive do trabalho, as parcerias público-privadas, a proteção dos negócios corporativos (MARTINS, NEVES, 2010).

Observando o modelo da Terceira Via, percebe-se que as parcerias públicoprivadas predominantemente visualizam as estratégias de manutenção e de desenvolvimento do mercado. E que as ações voltadas para a redução dos problemas sociais que se apresentam, servem de argumento para legitimar as políticas em prol do capital.

Analisando o papel do Estado atualmente no Brasil, identifica-se uma atuação mais efetiva do governo no estabelecimento de políticas direcionadas para as questões sociais. Estas iniciativas destacaram-se principalmente no fim do primeiro mandato do presidente Lula e permanecem sendo fortalecidas no atual governo da presidente Dilma.

Ao analisar as políticas educacionais em vigor no Brasil, percebe-se que estão em sintonia com os ditames da nova social democracia, ou Terceira Via, na medida em que mantém centralizadas as decisões sobre os rumos da educação nacional, descentralizam a execução dos programas, vinculam os recursos financeiros à adesão "voluntária" das políticas, disseminando e incentivando a performatividade e a consequente competição entre alunos e escolas, valorizando o mérito, adotando o modelo de administração gerencialista e focando de forma exacerbada nos resultados avaliativos.

Cóssio, Rodriguez e Leite (2012, p.07) corroboram com esta análise evidenciando que:

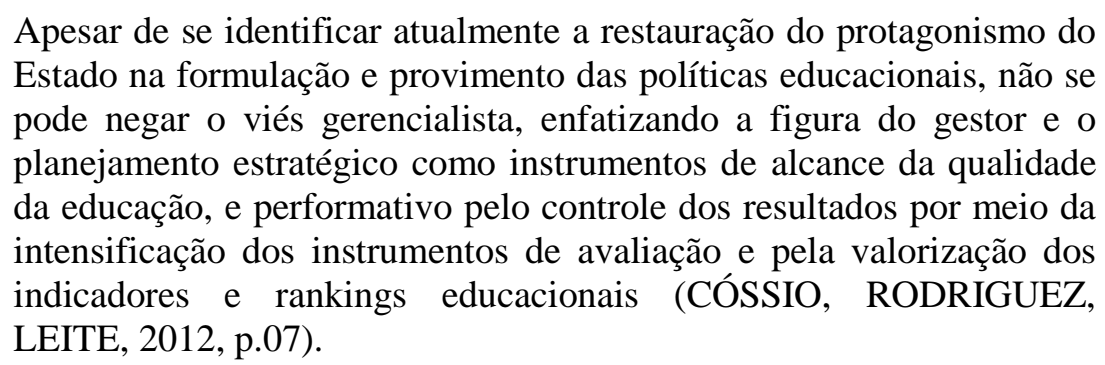

Peroni (2011, p.7) também contribui com está constatação ao descrever que, 
A política educacional em curso em tempo em que sustenta a democracia como princípio no âmbito da concepção, contraditoriamente, na sua materialização vem priorizando resultados avaliativos, competitivos, centralizadores e recorrendo a formas corporativas/coercitivas como mecanismos de controle (PERONI, 2011, p.7).

Não se pretende aqui negar a importância da preparação para o trabalho, considerando o trabalho um forte instrumento de inserção na vida social. Entretanto, esta formação não pode ficar restrita à técnica, ao saber fazer, é preciso avançar e superar a lógica instrumental assumida historicamente pela formação profissional. Preparar para o trabalho é preparar para pensar sobre o trabalho e seus processos, é preparar para ser sujeito.

\section{Formação do trabalhador: trabalho como princípio educativo}

As políticas educacionais analisadas referentes ao Ensino Médio, à Educação de Jovens e Adultos e à Educação Profissional, trazem a ênfase no currículo da formação para o mundo do trabalho, sendo importante compreender o trabalho como princípio educativo.

Para fundamentar e ampliar essa análise se apresenta a perspectiva de Marx, em O capital (1886-1867), referente à educação politécnica e tecnológica, como proposta de integrar o trabalho produtivo ao escolar. É necessário compreender esse debate teórico elaborado por Marx, no sentido amplo de educação politécnica, para uma formação geral que vincule a relação entre educação e prática social e o trabalho como princípio educativo. Partindo do princípio do que afirma Engels (2004, p.13), que o trabalho é a "condição básica e fundamental de toda a vida humana" e que o "trabalho criou o próprio homem", a natureza do homem é o trabalho, ou seja, sua ontologia 5 .

Ao retornar à concepção do trabalho como práxis humana, de desenvolver as condições necessárias à existência como produção histórica e das relações sociais, é impossível negar a centralidade do trabalho.

Em vez da substituição do trabalho pela ciência, ou ainda da substituição da produção de valores de troca pela esfera

${ }^{5}$ Termo aprofundado por Lukács. Para a ontologia do ser social o trabalho. Tradução do Prof. Ivo Tonet (UFAL), a partir do texto II Lavoro, primeiro capitulo do segundo tomo de Per uma Ontologia dell' Essere Sociale. Roma: Editori Riuniti, 1981. 
comunicacional ou simbólica, da substituição da produção pela informação, o que vem ocorrendo no mundo contemporâneo é uma maior inter-relação, maior interpenetração entre as atividades produtivas e as improdutivas, entre as atividades fabris e de serviços, entre atividades laborativas e as atividades de concepção, entre produção e conhecimento cientifico, que se expandem fortemente no mundo contemporâneo (ANTUNES, 2005, p.39).

Perante as metamorfoses do trabalho e sua organização é que se propõe uma nova relação com o conhecimento, trazendo em pauta as discussões sobre os objetivos da escola, a partir do reconhecimento de que se vive numa sociedade estruturada pelo capitalismo, mas sempre nas bases da contradição entre capital e trabalho.

Segundo Tumolo (2005, p.256) "O trabalho só poderia ser princípio balizador de uma proposta de educação que tenha uma perspectiva de emancipação humana numa sociedade baseada na propriedade social”. Pode-se indagar que o trabalho como princípio educativo é mais do que a apropriação, pelos que vivem do trabalho, de conhecimentos científicos, tecnológicos e sócio-históricos, é compreender as relações de trabalho na sociedade capitalista, que se diferencia do emprego e que se aproxima da natureza do próprio homem.

A reconfiguração do papel do processo educativo na formação do trabalhador ainda é um espaço de luta hegemônica do capital, no qual muitos trabalhadores ficam excluídos do sistema. É necessário romper com essa barreira desumanizadora do trabalho, criando condições para educar na perspectiva de ser um cidadão pleno, objetivando o papel da escola pela formação integral nas proposições da conscientização, da criticidade e dos conhecimentos científicos, sociais e culturais que perpassam o ser e fazer humano.

A escola deve ser voltada para uma formação polivalente, para uma formação teórica sólida. Com isso, estaria dando a sua contribuição para que o futuro trabalhador tivesse acesso às novas contribuições da ciência e da técnica que, por sua vez, deverão ser revolucionadas pelo coletivo dos trabalhadores (FRANCO, 1988, p. 86).

Após as considerações do autor, é importante ressaltar o papel da escola, a partir da concepção de educação que busca nas relações histórico-sociais o aporte para a construção, ressignificação e consolidação de conhecimentos, considerando os saberes constituintes dos sujeitos participantes do processo ensino-aprendizagem. Assim, o principio pedagógico não deve ser pautado na preparação para o mercado, mas no 
método de estudo e pesquisa, tendo por base as contradições da sociedade e do próprio trabalho que constitui o homem.

Sendo assim, o Ensino Médio, a EJA, a Educação Profissional, devem integrar as diferentes formas de educação para desenvolver saberes, habilidades e competências para a vida. Principalmente na base do entendimento da educação politécnica, que incorpora as relações de trabalho do homem com a formação cultural, o trabalho ativo na construção social e a ciência como uma prática generalizada e sistematizada que orienta essa atividade, de forma que cada um possa ocupar o lugar que lhe cabe.

$\mathrm{Na}$ base da criação de um projeto de ensino na perspectiva do trabalho como princípio educativo, ao ser considerado como essência humana, é possível articular os saberes existentes e produzir novos saberes em consonância com o avanço do conhecimento científico e tecnológico. Por essa concepção, propõe-se o desafio para uma nova configuração de educação comprometida com os jovens e adultos na perspectiva de dialogar com a complexidade da sociedade.

Nisso se assenta à proposição da defesa dos conhecimentos vivenciados, das especificidades de cada sujeito, da ressignificação das experiências e do envolvimento de todos na procura por qualidade de vida no contexto educativo, e assim compreender a formação permanente para além dos conhecimentos básicos como a cidadania e o desenvolvimento integral dos sujeitos.

\section{Considerações finais}

A presente pesquisa possibilitou a análise sobre as tendências e convergências nos estudos voltados para o campo das políticas educacionais nos estados do Rio Grande do Sul, Santa Catarina e Paraná, especificamente com relação às possíveis aproximações nos trabalhos apresentados sobre Ensino Médio, Educação de Jovens e Adultos e Educação Profissional.

Evidenciam-se algumas convergências, tais como a oferta conjunta (educação geral e formação para o trabalho) e a orientação legal voltada para a preparação para o trabalho.

Nas análises dos artigos sobre essas temáticas foram construídas categorias que aprofundam as possíveis articulações. Na primeira, em relação às transformações no mundo do trabalho e as suas relações com a educação, as discussões centram-se nas 
transformações dos processos de acumulação do capital e como estas estão influenciando e reestruturando o papel do processo educativo na formação do trabalhador.

Com base nas exigências do mundo do trabalho é que a população procura por escolarização, visando ocupar novas posições no mercado, e com isso alcançar melhores condições de vida e obter ascensão social. Nisso se assenta a segunda categoria, as políticas educacionais a partir das últimas reformas e as redefiniçõoes no papel do Estado, na qual as medidas para a garantia do direito à educação são necessárias à elevação da escolarização, que, por sua vez, se configura como credencial de entrada no mundo do trabalho.

$\mathrm{Na}$ terceira categoria discutiu-se a formação do trabalhador e, mais especificamente, o trabalho como princípio educativo, reiterando a centralidade do trabalho ao refletir a educação como processo permanente de construção de conhecimento. Sendo possível superar a concepção de ensino e de aprendizagem focada em aspectos técnicos, rumo a uma concepção epistemológica que busca a construção, ressignificação e consolidação de conhecimentos, considerando os saberes constituintes dos sujeitos participantes do processo ensino-aprendizagem.

A reflexão apresentada ressalta a importância dos debates na consolidação do campo de estudos das políticas educacionais. Neste sentido, se avalia como de grande importância o espaço de discussões que o evento da ANPAE - região sul oportunizou para os envolvidos no contexto da educação no âmbito regional, com repercussão nacional.

Embora as análises dos artigos não tenham se detido em avaliar quais os vínculos profissionais dos autores que produziram os trabalhos, percebeu-se que a grande concentração de pesquisas, conforme já tem sido apresentado como ponto de discussão e crítica do campo educacional no país, ainda está preponderantemente assentada nos programas de mestrado e doutorado. Portanto, se constata, mais uma vez, a distância que existe entre as pesquisas acadêmicas e os atores de base das escolas brasileiras.

Entende-se que a inclusão desses debates no contexto escolar pode possibilitar o processo de participação dos estudantes e, mais do que desenvolver a autonomia individual, tem o potencial de constituir-se como um elemento de ampliação cultural e instrumento necessário na luta pela transformação da sociedade atual. Para tanto, a aproximação tanto dos alunos quanto dos docentes nas discussões quanto aos objetivos 
e práticas das políticas educacionais, como parte de um projeto social amplo, se apresenta como ferramenta contra-hegemônica na busca de alternativas que priorizem a formação crítica e integral do ser humano.

\section{Referências}

ANTUNES, R. Adeus ao trabalho: ensaio sobre as metamorfoses e a centralidade do mundo do trabalho. 6. ed. São Paulo: Cortez, 1999.

ANTUNES, R. Capitulo I - A crise da sociedade do trabalho: fim da centralidade ou desconstrução do trabalho? In: ANTUNES, Ricardo. O caracol e sua concha: ensaios sobre a nova morfologia do trabalho. SP: Boitempo, 2005.

BARROSO, J. O Estado, a Educação e a Regulação das Políticas Públicas. Campinas: Educação \& Sociedade, 2005.

BRASIL. Ministério da Educação. Educação Profissional: Referenciais Curriculares Nacionais da Educação Profissional de Nível Técnico. Brasília, DF, 2000.

CIAVATTA, M. Formação profissional para o trabalho incerto: um estudo comparativo Brasil, México e Itália. In: FRIGOTTO, G (Org.). Educação e crise do trabalho: perspectivas de final de século. Petrópolis: Vozes, 1998, p. 100-137.

CÓSSIO, M. de F. Democracia neoliberal e globalização: triunfo, resistência e alternativas. 2010 (atualizado). Digitado.

CÓSSIO, M. de F; RODRIGUEZ, R. de C.; LEITE, M. L. Políticas Educacionais: entre a autoria e o controle. IX SEMINÁRIO INTERNACIONAL DE ETAPA E REDE, REDESTRADO, 2012, Santiago do Chile, Chile. Anais do IX Seminário Internacional de La Red Estrado, 2012.

CRUZ, R. M. Formação profissional e formação humana: os (des)caminhos da relação homem-trabalho na modernidade. In: AUED, B. W. (Org.). Educação para o (des)emprego. Petrópolis, RJ: Vozes, 1999.

ENGELS, F. Sobre o Papel do Trabalho na Transformação do Macaco em Homem. In: ANTUNES, R. A dialética do Trabalho: escritos de Marx e Engels. São Paulo: Expressão Popular, 2004.

FERRETTI, C. J. Empresários, trabalhadores e educadores - diferentes olhares sobre as relações trabalho e educação no Brasil nos anos recentes. In: LOMBARDI, J. C.; SAVIANI, D.; SANFELICE, J. L. (Orgs.). Capitalismo, trabalho e educação. Campinas, SP: Autores Associados, HISTEDBR, 2002. (Coleção Educação Contemporânea)

FRANCO, L. C. Trabalho da escola. In: FRANCO, L. C. A escola do trabalho e o trabalho da escola. $2^{\text {a }}$ ED. SP: Cortez: Autores Associados, 1988 
FREIRE, P. Direitos humanos e educação libertadora. In: FREIRE, Ana Maria Araújo (Org.) Pedagogia dos sonhos possíveis/ Paulo Freire. São Paulo: Editora UNESP, 2001.

MARX, K. O capital. Rio de Janeiro: Civilização Brasileira, 1975.

MARX, K. Processo de trabalho e processo de valorização. In: ANTUNES, R. A dialética do Trabalho: escritos de Marx e Engels. São Paulo: Expressão Popular, 2004.

MARTINS, A. S.; NEVES, L. W. A nova pedagogia da hegemonia e a formação/atuação de seus intelectuais orgânicos. In: NEVES, L. W. Direita para o social e esquerda para o capital: intelectuais da nova pedagogia da hegemonia no Brasil. São Paulo: Xamã, 2010.

PERONI, V. V. Mudanças no papel do Estado e políticas públicas de educação: notas sobre a relação público/privado. In: PERONI, V. V.; ROSSI, A. J. (orgs.). Políticas educacionais em tempos de redefinições no papel do Estado: implicações para a democratização da educação. Porto Alegre, Programa de Pós-Graduação em Educação da UFRGS, Gráfica e Editora da UFPEL, 2011.

SANTOS, B. S. Renovar a teoria crítica e reinventar a emancipação social. São Paulo: Boitempo Editorial, 2007.

TUMOLO, P. S. O trabalho na forma social do capital e o trabalho como princípio educativo: uma articulação possível? Educação e Sociedade. Campinas, vol.26, n 90, jan/abr.2005

\section{Como citar este artigo:}

SILVA, Simone Gonçalves et al. Políticas educacionais: aproximações entre ensino médio, EJA e educação profissional. Revista Ibero-Americana de Estudos em Educação, Araraquara, v.12, n.1, p. 278-293, 2017. Disponível em: <http://dx.doi.org/10.21723/riaee.v12.n1.8250>. E-ISSN: 1982-5587.

Data de submissão: dez/2015

Aprovação final: dez/2016 